\title{
Author Correction: Multi-region exome sequencing reveals genomic evolution from preneoplasia to lung adenocarcinoma
}

Xin Hu, Junya Fujimoto, Lisha Ying, Junya Fukuoka, Kazuto Ashizawa, Wenyong Sun, Alexandre Reuben (D), ChiWan Chow, Nicholas McGranahan, Runzhe Chen, Jinlin Hu, Myrna C. Godoy, Kazuhiro Tabata, Kishio Kuroda, Lei Shi, Jun Li, Carmen Behrens, Edwin Roger Parra, Latasha D. Little, Curtis Gumbs, Xizeng Mao, Xingzhi Song, Samantha Tippen, Rebecca L. Thornton, Humam Kadara, Paul Scheet, Emily Roarty, Edwin Justin Ostrin (D), Xu Wang, Brett W. Carter, Mara B. Antonoff 10 , Jianhua Zhang, Ara A. Vaporciyan, Harvey Pass, Stephen G. Swisher (D), John V. Heymach, J. Jack Lee (D), Ignacio I. Wistuba, Waun Ki Hong, P. Andrew Futreal, Dan Su \& Jianjun Zhang

Correction to: Nature Communications https://doi.org/10.1038/s41467-019-10877-8, published online 5 July 2019.

The original version of this Article contained an error in the Data Availability Statement. The accession code indicated 'EGAS00001004960' and should have read 'EGAS00001003439'. This has been corrected in both PDF and HTML versions of the Article.

Published online: 12 May 2021

Open Access This article is licensed under a Creative Commons Attribution 4.0 International License, which permits use, sharing, adaptation, distribution and reproduction in any medium or format, as long as you give appropriate credit to the original author(s) and the source, provide a link to the Creative Commons license,
and indicate if changes were made. The images or other third party material in this article are included in the article's Creative Commons license, unless indicated otherwise in a credit line to the material. If material is not included in the article's Creative Commons license and your intended use is not permitted by statutory regulation or exceeds the permitted use, you will need to obtain permission directly from the copyright holder. To view a copy of this license, visit http://creativecommons.org/licenses/by/4.0/.

(C) The Author(s) 2021 